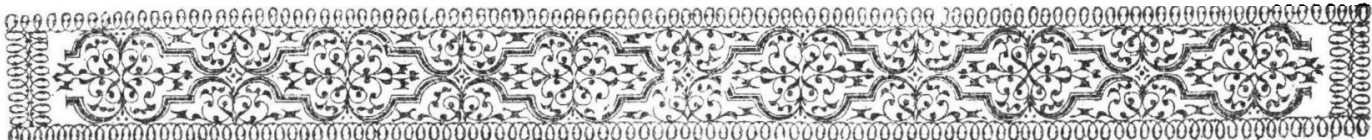

\title{
DAS ALTARWERK MARTEN HEEMSKERCKS FÜR DIE LAURENTIUSKIRCHE ZU ALKMAAR
}

VON

AXEL L. ROMDAHL.

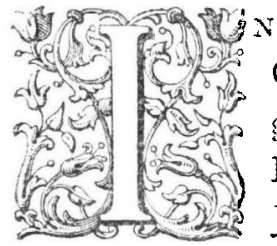

dem schönen alten Dom zu Linköping in Schweden (Provinz

Ostgothland) hängt - leider an einer in jeder Hinsicht ungünstigen Stclle - ein kolossaler Flügelaltar von MARTEN HEEMSKERCK.

Er wurde im Jahre ${ }_{5} S \mathrm{I}$ der Kirche von dem clamaligen Könige

JoHAN III geschenkt. Ein Notizverfasser aus dem Ende des Iten Jahrhundert wollte wissen, dass das Werk anfangs für Gross-Novgorod bestellt, dann aber durch Schiffbruch nach Schweden gekommen wäre. Wie der Altar an seinen jetzigen Aufbewahrungsort gelangte, hat sich bisher sonst nicht ermitteln lassen; von der ersten Bestimmung und der Herstellung desselben geben uns dagegen einige Aktenstiicke in VAN DER WILligENs „Les Artistes de Harlem" die reichsten und sichersten Auskinfte. Es sind die Kontrakte und Rechnungen, die sich auf ein Hauptwerk inARTEN HEEMsKERCKS, den grossen Flügrelaitar für die Laurentiuskirche in Alkmaar, beziehen. KAREL VAN MANDER spricht von demselben als verschollen, durch Vergleich der Urkunden mit dem Altarwerke zu Linköping lässt er sich aber wiederfinden.

Nach dem ersten Uebereinkommen von dem 25 September 1538 sollte in den Mitteltafeln oben die Kreuzigung und unten die Kreuztragung dargestellt werden . Dies ist auch in Linköping der Fall, und die Kreuzigung ist bezeichnet MARTINVS HEEMSKERCK ME FECIT FIERI AO MDXL, eine Jahreszahl, die mit der festgesteilten Vollendungszeit der Alkmaarer Mittelbilder völlig übereinstimmt. Dagegen fehlen die Grisaillelunetten mit Propheten und Sibyllen, die in dem Kontrakt genannt sind. Wahrscheinlich sind sie geopfert um einen grösseren Figurenmasstab zu ermöğlichen.

Von den inneren Flügelbildern wurde am is November 1539 kontraktiert. 
Links oben wollte man eine Darstellung Christi mit einem Bildniss des Bisschofs von Utrecht, GEORG voN EGMOND, haben und in der entsprechenden Tafel rech:s die Auferstehung mit einem Porträt des Abtes von dem Stifte Egmond, Willem VAN DER GOES. Statt des Letztgenannten, wenn er sich nicht gemalt wünschte, sollte ein anderer z. B. Pieter Claesz. Palinck ${ }^{1}$ ), abgebildet werden. Die unteren Tafeli waren für Passionsscenen und Bildnisse des Pfarrers Jheronimus Jansz. bestimmt. Der Altar zu Linköping zeigt links oben die Darstellung Christi vor dem Volke, rechts oben die Auferstehung, unten links die Stäupung und rechts die Verspottung. Das Bildniss des Bischofs ist in dem Auferstehungsbilde; er kniet im Amtsgewand vor einem mit den Initialen G. E. und seinem Wappen geschmückten Betstuhl. Unter den lärmenden Gestalten auf dem Ecce Homobilde bemerken wir einen ruhigen und würdigen Herrn in blauem pelzbesetzten Mantel und grauen Handschuhen. Durch einen Zettel als Nicodemus gekennzeichnet, ist es doch sicher ein Porträt, nicht unwahrscheinlich von dem erwähnten Pieter Clafesz. Palinck. Die unteren Innenflügel entbehren Bildnisse. Der Maler hat einen besseren Platz für die betreffenden Herren gefunden.

Am I 2 März I 54 I wurden die äusseren Flügelmalereien bestellt : oben das Martyrium des heiligen Laurentius und die Vertheilung des Kirchenschatzes unter die Armen, unten das Abendmahl und Christus am Oelberg. Wir sehen in Linköping das Program gefolgt, freilich mit der Änderung, dass die Geburt Christi statt des Oelberges dargestellt ist. Bei der Vertheilung des Kirchenschatzes (rechts oben) ișt der heilige Diakon von den Vorstehern der Laurentiuskirche assistiert. Da haben wir also den Pfarrer und den Schatzmeister zu suchen, die in den unteren Innenflügeln nicht mitkamen. Auch bei dem Martertod des Heiligen ist ein Stifter in Zeittracht anwesend, und zwar - wie es scheint - ein Klostergeistlicher, wohl der Abt Willem VAN DEK GOES. Die Aussenflugel sind ganz oben mit der Jahreszahl I 542 bezeichnet, was auch zu den alten Aktenstücken passt.

Der Eindruck den wir von dem grossen Altarwerk zu Linköping bekommen ist jedenfalls nicht sehr erfreulich. Der Ton ist unangenehm kalt, blau und im Nackten stumpf röthlich, die Gesichter sind schrecklich, leer und grimacierend, nur die Bildnisse sind etwas besser; kurz - wir erkennen MARTEN HEEMSKERCK wie er auch sonst sich zeigt. Holland hat mit diesem Gemälde nicht viel verloren, Schweden nicht viel gewonnen, aber historisch verdient es einige Aufmerl:samkeit wegen seiner Grösse und wegen der Vollständigkeit, womit wir die Herstellung desselben kennen.

1) Siehe von diesem Kronijk van het Historisch Genootschap, 1859 S. 55-56 